\title{
JUNIOR ENTREPRENEURSHIP HUMAN INTERACTIONS SKILLS METHOD
}

\author{
C. Costa-Lobo ${ }^{1}$, M. Magalhães ${ }^{2}$, C. A. Collazos ${ }^{3}$, J. Cabrera ${ }^{4}$, P. Asnes ${ }^{5}$, \\ C.S. González-González ${ }^{6}$, D.F. Escudero ${ }^{7}$, H. Ortega Neri ${ }^{8}$, T. Carvalho ${ }^{9}$, \\ F. Moreira ${ }^{10}$ \\ ${ }^{1}$ Cátedra de Juventude, Educação e Sociedade da UNESCO, INPP \& REMIT- Universidade \\ Portucalense, IESFafe (PORTUGAL) \\ ${ }^{2}$ REMIT-Universidade Portucalense (PORTUGAL) \\ ${ }^{3}$ University of Cauca (COLOMBIA) \\ ${ }^{4}$ Universidad Autónoma de Madrid (SPAIN) \\ ${ }^{5}$ Universidade Portucalense Infante D Henrique- INPP (PORTUGAL) \\ ${ }^{6}$ Universidad de La Laguna (SPAIN) \\ ${ }^{7}$ Universitat Ramon Llull (SPAIN) \\ ${ }^{8}$ Universidad Autónoma de Zacatecas (MEXICO) \\ ${ }^{9}$ Governo do Estado do Maranhão-Sao Luis (BRAZIL) \\ ${ }^{10}$ REMIT, IJP - Universidade Portucalense \& IEETA - Universidade de Aveiro (PORTUGAL)
}

\begin{abstract}
Career education emerge in a context of a society where the importance of the ability to anticipate change, adapt to new circumstances, and invent new business practices is explicit. Some social and educational dissatisfaction occurs when the school focuses almost exclusively on the development of the convergent thinking of the students, forgetting the creativity in a divergent and contextual sense. Assuming that creativity is a phenomenon that involves higher levels of consciousness and complexity are addressed didactic options for the pedagogical training of teachers and for the organization of curricular and extracurricular activities of the school, in order to develop participation, problem solving and decision-making, reflection, interaction (through teamwork and networking), teamwork between individuals with different backgrounds, and joint decision-making among actors with complementary. This paper, regarding the entrepreneurial skills, and regarding previous research on entrepreneurship and entrepreneurship education, stresses the role of human interactions skills (HIS) to the success of the entrepreneurial process, both in terms of opportunity discovery/generation and of its exploitation. Entrepreneurship is increasingly regarded as a social process embedded in social structures. One of the most important results of the project-based approaches to learning, strongly recognized in the literature is the development of students' HIS. This view assigns a pivotal role to social capital and to networking in the entrepreneurial process, which can be a complex process requiring the combination of several technological and non-technological competences and resources. These are often external to the entrepreneurial team and distributed across a multiplicity of actors. Networking is therefore a central skill in the entrepreneurial mindset, acting as facilitators in the process of information and resource gathering and in the learning process (learning by interacting). Furthermore, entrepreneurship is frequently a team effort and therefore teamwork skills become central. We emphasize that for entrepreneurship it is indispensable to consider the competence of sustainability, oriented in the objectives of sustainable development for society, as well as the valuation in the local identity of the same with global projection. The Junior Entrepreneurship Human Interactions Skills (JEANS) Method, using a curriculum supported by innovative material and technological resources, enhancing formative evaluation, aims to provide the students the experience to identify and exploit an innovative business idea and develop a project. The steps of training, training carried out and the research plan to assess the competences developed by the JEANS Method are revealed.
\end{abstract}

Keywords: Entrepreneurship education, Creativity, Human Interactions Skills (HIS), Teaching and learning approaches.

\section{INTRODUCTION}

Entrepreneurship is increasingly regarded as a social process embedded in social structures [1], [2]. One of the most important results of the project-based approaches to learning, strongly recognized in the literature (e.g., [1]) is the development of students' human interaction skills. This view assigns a 
pivotal role to social capital and to networking in the entrepreneurial process, which can be a complex process requiring the combination of several technological and non-technological competences and resources [3], [4]. The uniqueness of entrepreneurial education is already established in the literature (e.g., [5], [6], [7]).

Entrepreneurship is increasingly regarded as a social process embedded in social structures. Career education emerge in a context of a society where the importance of the ability to anticipate change, adapt to new circumstances, and invent new business practices is explicit [8].

Some social and educational dissatisfaction occurs when the school focuses almost exclusively on the development of the convergent thinking of the students, forgetting the creativity in a divergent and contextual sense. Assuming that creativity is a phenomenon that involves higher levels of consciousness and complexity are addressed didactic options for the pedagogical training of teachers and for the organization of curricular and extracurricular activities of the school, in order to develop participation, problem solving and decision-making, reflection, interaction (through teamwork and networking), teamwork between individuals with different backgrounds, and joint decision-making among actors with complementary [9]. There is a need for more training in Creativity for the educational field in particular and in other dimensions that have to do with greater social, cultural and ecological responsibility [9]. The trends in Creativity reflect that Creativity is related to ethical implications and social improvement, as well as self-training [9]. The references of complexity and transdisciplinarity have valuable implications in contexts of didactic innovation, methodologies and evaluation.

One of the most important results of the project-based approaches to learning, strongly recognized in the literature is the development of students' HIS. This view assigns a pivotal role to social capital and to networking in the entrepreneurial process, which can be a complex process requiring the combination of several technological and non-technological competences and resources. These are often external to the entrepreneurial team and distributed across a multiplicity of actors. Networking is therefore a central skill in the entrepreneurial mindset, acting as facilitators in the process of information and resource gathering and in the learning process (learning by interacting). Furthermore, entrepreneurship is frequently a team effort and therefore teamwork skills become central. We emphasize that for entrepreneurship it is indispensable to consider the competence of sustainability, oriented in the objectives of sustainable development for society, as well as the valuation in the local identity of the same with global projection.

Regarding the entrepreneurial skills, previous research on entrepreneurship and entrepreneurship education stresses the role of soft skills to the success of the entrepreneurial process, both in terms of opportunity discovery/generation and of its exploitation.

Entrepreneurs need skills to discover [10] and/or generate [11], [12] the opportunity, to identify, gather information and analyse several sources of new ideas and factors that shape their feasibility, to evaluate their success, to develop them and to overcome the critical junctures.

Entrepreneurial mindset and skills will therefore include, for example, ability of identifying opportunities, creative thinking, problem-solving, autonomy, negotiating, argumentation, thinking strategically, becoming persistent and more resilient to failures [13], [14].

In fact, many scholars now agree that traditional pedagogical approaches are insufficient to adequately develop entrepreneurial skills and mindsets. Traditional approaches fail to deal with the complexity and uncertainty of the entrepreneurial process, to prepare students to think like entrepreneurs and to mobilize entrepreneurship skills and attitudes in their jobs, even when they do not become entrepreneurs [2]. There is no consensus about the most appropriate teaching models for entrepreneurship, or about the ways to assess the impact of entrepreneurship courses (e.g., measuring it in educational terms through the impact on students' skills or on the number of start-ups funded by alumni) [5]. Currently entrepreneurship is increasingly included in the curricula of undergraduate courses [15]. This is linked essentially to the development of attitudes, skills and actions that are critical to the development of an entrepreneurial mindset [16].

Entrepreneurial education needs to encourage creativity and innovation and promote the emergence of new ideas [15].

Learning approaches should include learning by doing, learning by experimenting, learning by coping, learning by interacting, project-based learning, learning from mistakes in a group context [17]. Entrepreneurship is frequently a team effort and therefore teamwork skills become central [2]. 


\section{METHODOLOGY}

The Junior Entrepreneurship Human Interactions Skills (JEANS) Method, is a methodology applied in the discipline of entrepreneurship in the elementary school course in a private educational institution located in Porto, in the north of Portugal.

The ethical procedures underlying the intervention and research recommended by the Code of Ethics of the American Psychological Association (APA) were complied with the general principles of: respect for the dignity and rights of the person were respected and the vocational decisions of the students were respected; the competence on the part of the teacher, exercising its activity in consonance with technical-scientific assumptions and training for implementation of the JEANS Method; beneficence and non-maleficence, protecting the legitimate interests of students and tailoring classes to their needs [18]. Some specific ethical principles were also followed. First, privacy and confidentiality were ensured, and data were stored. Second, professional relations were respected and there was mutual respect among faculty members and other professionals / educational agents. Third, there was professional care in the evaluation, using valid and scientifically substantiated protocols, safeguarding the proper supervision, protection and safety of the materials. Fourth, professional care was considered in the intervention, as potential situations of conflicts of interest between clients and institutions were prevented [18]. Fifth, ethical procedures underpinning research were respected, ensuring scientific integrity [18], [19].

The JEANS Method, Figure 1, consists of four steps:

1 Group composition - the groups are randomly constituted so that a response to a problem/market need is given, allowing to evaluate the set of students' competences in different contexts and with different compositions of participants (team);

2 Tasks execution - the number of tasks performed is directly related to the year / grade in which it will be applied (varies between 3 and 5);

3 Assessment - assessment is carried out at the end of each school year;

4 Process control - the control method is monitored in all its extension by the internal and external teachers to the institution, through "pitchs" made by the students, where the domain of the canvas model is evaluated, with the objective of evaluating the domain of the own methodology, ability to work as a team versus individual work, allowing continuous improvement to find a solution (idea) to solve a given problem (10th and 11th) or the need to identify a problem / need in the market (12th).

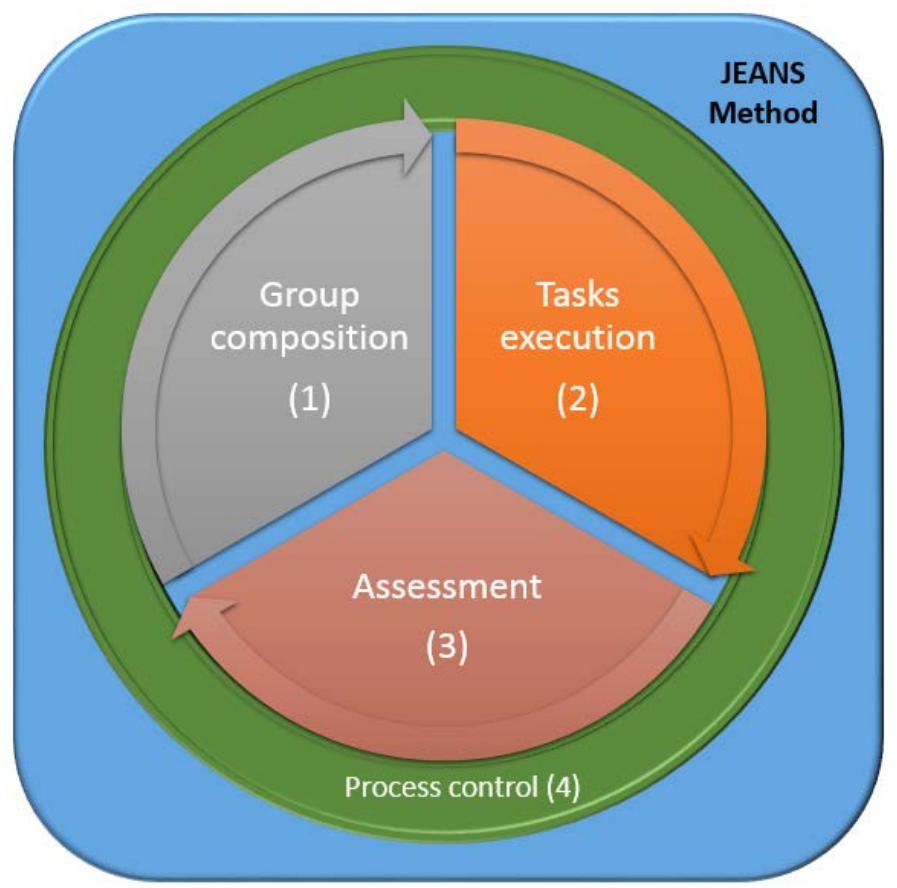

Figure 1. The Junior Entrepreneurship Human Interactions Skills (JEANS) method. 
Step (2) of the JEANS method consists of at least 3 tasks and a maximum of 5 tasks, with the first three tasks to be carried out over the three years of application, the four tasks applied in the last two years and the total tasks applied only the last year, as can be seen in Figure 2.

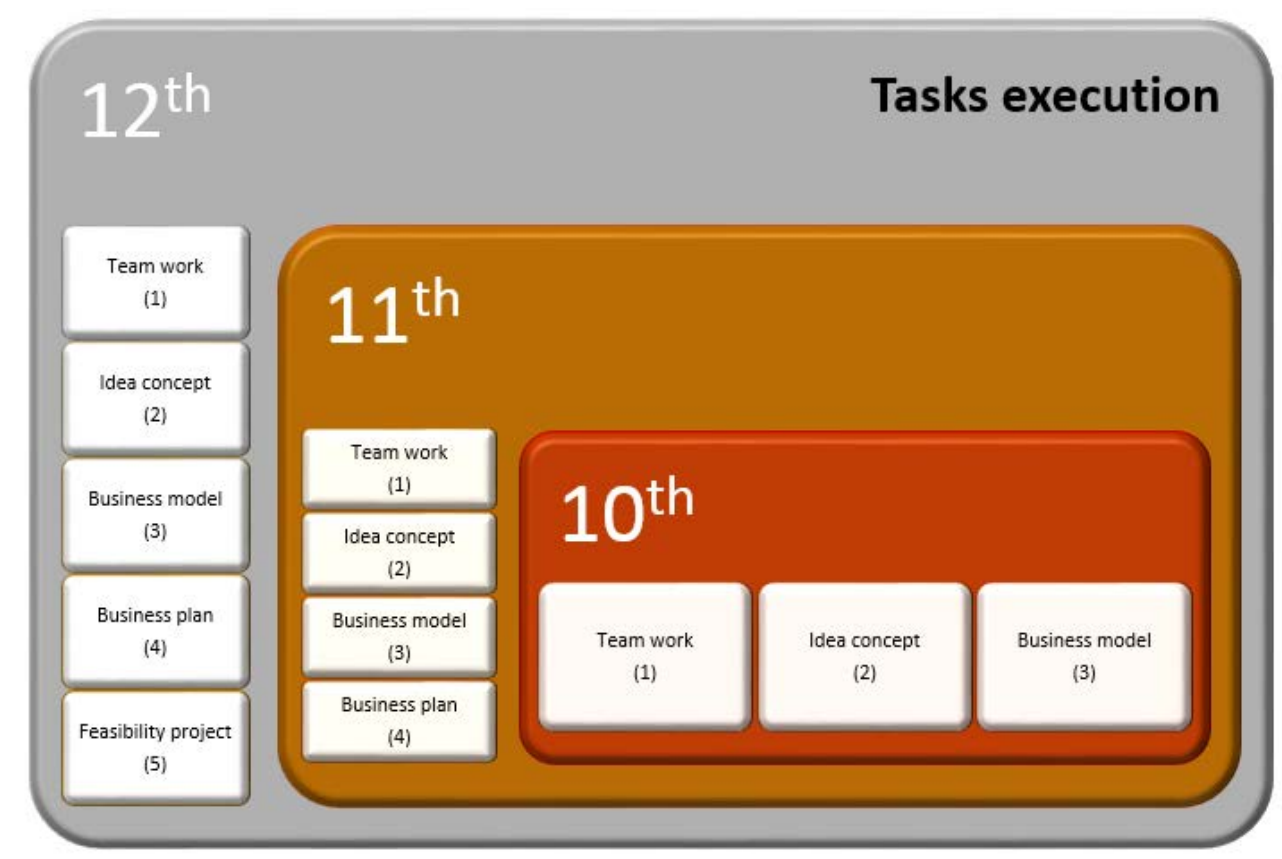

Figure 2. Tasks execution by school year.

The discipline of Entrepreneurship is taught over three consecutive school years, in the 10th, 11th and 12th grade. Regardless of the curricular year, we intend to apply the JEANS method (Figure 1, and 2) to evaluate soft skills and hard skills.

The curricular program presents different degrees of difficulty, taking into account the curricular year. Each class varies from a minimum of 20 students to a maximum of 30 , and they are required to be grouped into work groups, a minimum of three and a maximum of four students. After the groups are formed (step (1), Figure 1), the tasks are indicated. The students in grades 10 and 11 are presented with a "problem" and are asked to formulate a set of "ideas" to choose the one that best represents the "solution" to the identified "problem". While the 12th graders are asked to identify a "problem" and its resolution.

In the three pitches made during the school year, the teachers' ability to "work as a team" is evaluated (1). Allowing, demonstrating that solving the problem or a team need is more efficient and effective than individual work. But it is also an opportunity to prepare young people for the job market. Second, from an "idea" (2) find out whether students are able to find a solution to the "problem". Third, students demonstrate capabilities to fill the Canvas Model, which will serve to explain the proposed business model (3). Having validated the business model, demonstrate how able to write the Business Plan (4) of your project, know how to communicate it. Lastly, finally, to support the feasibility project (5).

In terms of tasks (Figure 2) to be carried out, students in the 10th grade are only required to design the business model for the idea / project, for students in the 11th grade, a business plan is required. And the students of the 12th grade, in addition to the previous tasks, are required the technical and economic feasibility of the idea / project, which is called business validation.

\section{RESULTS}

The Junior Entrepreneurship Human Interactions Skills (JEANS) Method, using a curriculum supported by innovative material and technological resources, enhancing formative evaluation, provides the students the experience to identify and exploit an innovative business idea and develop a project. 
This method has been applied since 2014 with great success, evidenced in the evaluation carried out in more than 126 Pitchs by the own professor of the discipline of entrepreneurship, but also, by the invited Professor, in the open day realized all years for this educational institution.

1 It was demonstrated that in group students are able to develop and better ideas / solutions to solve the problem (97\%);

2 From pitch to pitch, there is a continuous improvement of the group of students (92\%);

3 This is a new way of learning - "learning by doing".

Since the implementation of this method, the program of studies has completed three cycles of complete studies of activity, related to the triennia from 2014 to 2016, from 2015 to 2017 and from 2016 to 2018, where up to now, about 84 students have attended the entrepreneurship discipline, and only four groups did not succeed in assessment, they were not able to work as a team.

In general, the Junior Entrepreneurship Method for Human Interactions (JEANS) presents an appreciable degree of maturity, and it would now be interesting to disseminate it to other educational institutions in Portugal, in order to confirm the consistency and effectiveness of this method: Skills and Abilities.

This experience is facilitated and boosted using several different pedagogical practices and learning activities. JEANS method, transformer and creative method, develops competences that are recognized as central in the entrepreneurship mindset, such as, teamwork, communication, critical thinking, creative thinking, problem-solving, argumentation, networking, resilience and leadership, skills of utmost importance in the knowledge-based economy and preparing students for their working life.

The results indicate that this method is a useful tool to develop entrepreneurship skills of utmost importance in the knowledge-based economy and preparing students for their working life. The JEANS Method develops competences that are recognized as central in the entrepreneurship mindset. This entrepreneurship education method is based on the principle of "learning by doing", with a particular focus on project-based learning and also on team based-learning. JEANS method, transformer and creative method, develops competences that are recognized as central in the entrepreneurship mindset, such as, teamwork, communication, critical thinking, creative thinking, problem-solving, argumentation, networking, resilience and leadership, skills of utmost importance in the knowledge-based economy and preparing students for their working life.

The data obtained allows to conclude in general that the pattern of findings of JEANS Method evaluation is favorable, the results are very encouraging supporting initial hypothesis that JEANS Method significantly enhance human interaction skills without requiring any change to prior curricula.

\section{CONCLUSIONS}

Some social and educational dissatisfaction occurs when the school focuses almost exclusively on the development of the convergent thinking of the students, forgetting the creativity in a divergent and contextual sense. In this debate there is always some tension that occurs under the difficulties of the experts to reach consensus on a definition of creativity, and then to point out guidelines for their evaluation and training.

This complex and transdisciplinary vision of creativity, we can apply it in different areas on a personal and social-cultural level. From the astounding talents that increasingly appear every day in children and adolescents from different countries, small inventors, scientists and artists with extraordinary qualities and with whom pedagogy has a great responsibility, as well as with all children empowering Their abilities and competences to express their uniqueness and their relationships with others, to generate an inclusive and respectful environment, and of course not, also considering the environment of which it is part, to generate more contextualized learning in a system that integrates local heritage, Artistic and cultural, in the neighborhoods, the city, and consider as part of the principles, a conscience and ethics that contributes to the care needs of the ecosystem and the planet. With this model of trends in creativity, we can promote a favorable impact in educational communities, whenever a system-wide renovation is proposed: its mission and vision, its community (managers, students, families and other members), their methodological strategies (project-based learning, others), their resources (space, technology, and materials), their activities, their network connections, etc. This requires the participation of the entire community, both in training, and in the design and implementation of innovative projects. 
The Junior Entrepreneurship Human Interactions Skills (JEANS) Method, transformer and creative method, is still very recent, is based on the principle of "learning by doing", with a particular focus on project-based learning and also on team based-learning [1].

It is also worth noting the need to carry out further research to evaluate the effectiveness of the JEANS Method, to analyze variations according to personality characteristics and to attest to the effectiveness of the interventions [20], [21]. It would also be useful to test the applicability and impact of the JEANS Method with specific groups such as gifted youth [22].

This research, although focused on the educational intervention in entrepreneurship, can contribute to a line of research on youth, education and society, particularly in the framework of UNESCO's 812 Chair, stimulating the intersection of interests and the realization of educational practices integration between youth, education and society.

It would now be desirable to disseminate this method in other types of educational establishments, namely in public education, in order to validate the effectiveness and efficiency of this method. This analytical work, does not allow time to assess the prevalence of the presented analysis, which leads us to believe that this is the limitation of the assessment methodology implemented in this JEANS Method editions and suggests to conduct an international longitudinal study, at the next edition of the project, that may enhance the examination of the temporal relationships between variables and the degree to which the predictors may be relevant to the change of criterion variables, as explained by social cognitive theory of career [1], [8].

This paper, regarding the entrepreneurial skills, and regarding previous research on entrepreneurship and entrepreneurship education, stresses the role of human interactions skills (HIS) to the success of the entrepreneurial process, both in terms of opportunity discovery/generation and of its exploitation.

\section{REFERENCES}

[1] C. Costa-Lobo, "Abordagem sócio-cognitiva do ajustamento à carreira no ensino superior: o papel das actividades em grupo, da auto-eficácia e dos interesses," (Tese de Doutoramento). Escola de Psicologia, Universidade do Minho, Braga, Portugal, 2011.

[2] C. Sousa, M. Magalhães, F. Castro Lopes, S. Fernandes, C. Costa-Lobo, "EHIS Method(): Entrepreneurship Human Interaction Skills," In Christophe Loué \& Sonia Ben Slimane (Eds), Proceedings of the 12th European Conference on Innovation and Entrepreneurship ECIE 2017, pp. 644-652, 2017.

[3] E. Autio, "New technology-based firms in innovation networks sympletic and generative", Research Policy, vol 26, pp 263-81, 1997.

[4] P. Mustar, M. Renault, M. Colombo, E. Piva, M. Fontes, A. Lockett, M. Wright, B. Clarysse, N. Moray, "Conceptualising the heterogeneity of research-based spin-offs: a multi-dimensional taxonomy", Research Policy, vol. 35, no.2, pp 289-308, 2006.

[5] A. Gibb, "Entrepreneurship: Unique Solutions for Unique Environments: Is it possible to achieve this with the existing paradigm?", Working Paper 038/2006. National Council for Graduate Entrepreneurship (NCGE) UK, 2006.

[6] D. Politis, "The Process of Entrepreneurial Learning: A Conceptual Framework", Entrepreneurship: Theory and Practice, vol. 29, no. 4, pp 399-424, 2005.

[7] D. Rae, "Universities and enterprise education: responding to the challenges of the new era", Journal of Small Business \& Enterprise Development, vol. 17, no.4, pp 591-606, 2010.

[8] C. Costa-Lobo, A. T. Ferreira, "Educação para a Carreira: Contributos para a Tomada de Decisão nas Transições Profissionais," In: Alves, J. S. \& Neto, A. M. S. (org.), Decisão: Percursos e Contextos, pp. 201-206, 2012.

[9] C. Costa-Lobo, J. Cabrera, "Teacher training: the relevance of creativity in schoo,". In Paulo Alberto da Silva Pereira, Osman Titrek, Gozde Sezen- Gultekin (Eds.), Proceedings of 3rd International Conference on Lifelong Education and Leadership for All, pp. 156-165, 2017.

[10] R. A. Baron, S. A. Shane, "Entrepreneurship: a process perspective," Mason, OH: Thompson, 2005. 
[11] N. F. Krueger, "The cognitive infrastructure of opportunity emergence," Entrepreneurship Theory and Practice, vol. 24, no.3, pp 5-23, 2000.

[12] Y. Sarason, T. Dean, J. F. Dillard, "Entrepreneurship as the nexus of individual and opportunity: a structuration view," Journal of Business Venturing, vol. 21, pp 286-305, 2005.

[13] M. Täks, P. Tynjälä, H. Kukemelk, "Engineering students' conceptions of entrepreneurial learning as part of their education," European Journal of Engineering Education, vol. 41, no.1, pp 53-69, 2016.

[14] M. van Gelderen, "Autonomy as the guiding aim of entrepreneurship education," Education+ Training, vol. 52, no.8/9, pp. 710-721, 2010.

[15] D. Kuratko, "The Emergence of Entrepreneurship Education: Development, Trends and Challenges," Entrepreneurship Theory and Practice, vol. 29, no. 5, pp 577-597, 2005.

[16] H. M. Neck, P. G. Greene, C.G. Brush, "Teaching entrepreneurship: A practice-based approach," Edward Elgar Publishing, 2014.

[17] D. Higgins, K. Smith, M. Mirza, "Entrepreneurial Education: Reflexive Approaches to Entrepreneurial Learning in Practice," The Journal of Entrepreneurship, vol. 22, no.2, pp 135-160, 2013.

[18] Regulamento n. ${ }^{\circ}$ 258/2011 de 20 de abril. Diário da República n. ${ }^{\circ}$ 78/2011, Série II, Ordem dos Psicólogos Portugueses, 2011.

[19] American Psychological Association, "Publication manual of the American Psychological Association," Washington, DC: American Psychological Association, 2010.

[20] K. Öztemel, "Career indecisiveness of turkish high school students: associations with personality characteristics," Journal of Career Assessment, no. 22, pp. 666-681, 2014

[21] F. Silva, S. Oliveira, P. Barroso, I. M. Oliveira, M. C. Taveira, P. Cardoso, "Life design counseling: Uma intervenção de carreira no serviço de psicologia de ação social municipal," In M. Carvalho, \& M. C. Taveira (Eds.), Intervenções de carreira: Estudos de casos práticos, pp. 89-109, 2017 